\title{
The Hydrated and Hydrolyzed States of Exchangeable Cations in the Montmorillonite and Their Quantitative Assessment
}

\author{
Alexei Maftuleac \\ Institute of Chemistry, Academy of Sciences of Moldova, Chisinau, Republic of Moldova
}

Email address:

alexei.maftuleac@yahoo.com, amaft@mail.md

To cite this article:

Alexei Maftuleac. The Hydrated and Hydrolyzed States of Exchangeable Cations in the Montmorillonite and Their Quantitative Assessment. International Journal of Materials Science and Applications. Vol. 4, No. 2, 2015, pp. 124-129. doi: 10.11648/j.ijmsa.20150402.19

\begin{abstract}
In the paper is submitted opinion according to which, a part of the hydrated exchangeable cations in the montmorillonite is hydrolyzed. A new experimental method has been proposed, which allows to estimate the hydrated/hydrolyzed state of these cations. The method consists in the use of thermal analysis data of mineral, and is particularly effective in the study of homoionic forms of montmorillonite. The mathematical formulas have been proposed for processing the obtained experimental data.
\end{abstract}

Keywords: Thermal Analysis, Montmorillonite, Exchangeable Cations, Interlayer Water, Hydrolyzed Cations, Mathematical Processing of Data

\section{Introduction}

The montmorillonite is a widespread aluminosilicate mineral having large application in various industries [1-4]. As demonstrated by spectroscopic studies, this material might be present on others celestial bodies, such as Mars, comets and asteroids [5-10]. Due to the chemical composition and its layered structure, the montmorillonite has a good adsorption, ion-exchange and catalytic properties. Some researches consider that this mineral could be a "matrix" on whose surface was realized the chemical synthesis of complex of substances which have become the basis of proto-life on the Earth [11-14]. The montmorillonite is an interesting object of study for specialists in various fields of science - geologists, chemists, physicists, ecologists etc. In the study, the scientists use sophistical equipment and methods such as Raman and IR spectroscopy, X- Ray and thermal analysis and others [15-17]. The current level of development of techniques and informational technologies allows the automating processes to study the minerals. But it also requires developing the mathematical methods for processing these experimental data. The thermal analysis shows that upon heating of cation-exchanged montmorillonite they lose water, and this process occurs in few stages. First dehydration of samples occurs at $80-250^{\circ} \mathrm{C}$, followed by their dehydroxilation at $450-800^{\circ} \mathrm{C}$. Further heating is accompanied by processes of recrystallisation, amorphing and formation of new phases (interval $850-950^{\circ} \mathrm{C}$ ) [17-19].

It was observed that dehydration process of varies homoiones samples of montmorillonite is marked by appea rance on a DTA curve of a simple or double endothermal effect, the form of which depends of the nature of the exchanged cation and of its state [19]. The remove of these two types of water with minima on DTA, 180 and $200-210^{\circ} \mathrm{C}$, is accompanied by mass losses, easily identified by the steps on TG curve. The respective changes are marked likewise on DTG curve at the temperature, on which appear the endothermal effects on DTA curve.

\section{Experimental Methods and Instruments}

Sometimes, for scientific or practical purpose (in production) it is necessary to know the nature and hydration degree of interlayer cations of montmorillonite. In their scientific work [20] the authors proposed the following interesting method to determining this parameter. Let's consider adsorption of water vapors on modified samples of montmorillonite with exchanged cation. It is know that the adsorption isotherms plotted in standard variables of BET equation are linear for the small value of $P / P_{s}=0.05-0.35$. 
Under such conditions the "monolayer capacity" $A_{m}$ obtained from BET equation is essentially a measure of the number of water molecules in the interlayer space of the adsorbent. The authors suggested using this conclusion in order to calculate the number of water molecules per interlayer cation:

$$
N_{\mathrm{H}_{2} \mathrm{O} / \mathrm{cat}}=\frac{A_{m} Z}{E}
$$

where $A_{m}$ is the monolayer capacity (from BET) in $m M o l e s / g$, $E$ is the exchange capacity of the mineral in $m e q / g$ and $z$ is the electric charge (conventional unites) of the cation.

However the measurement of adsorption isotherms using vacuum chamber is a difficult and time consuming procedure. Therefore it was necessary to find a simple and convenient method for determining the hydration number of interlayer cations of montmorillonite. The most promising in this respect is the thermal analysis. In the experiments [19] with montmorillonite from Republic of Georgia ( $\mathrm{Na}, \mathrm{Ca}, \mathrm{Al}, \mathrm{Fe}$ modifications of Ascangel, Derivatograph of MOM, Hungary) it was demonstrated that the amount of adsorption water eliminated from cation-exchanged samples upon programmed heating, depends of the nature of interlayer cation, and the two kinds of water registered on DTA curves (as well as on DTG), are in a certain quantitative relationship clearly observed from TG curves (Fig.1). Also, this relationship depends on the $\mathrm{pH}$ of the solution in which these samples were prepared. Georgian montmorillonite (Ascangel) is characterized by the thermal effects that are well distinguished on derivatograme during thermal analysis. Due to these properties it has been used as object of study in our research.

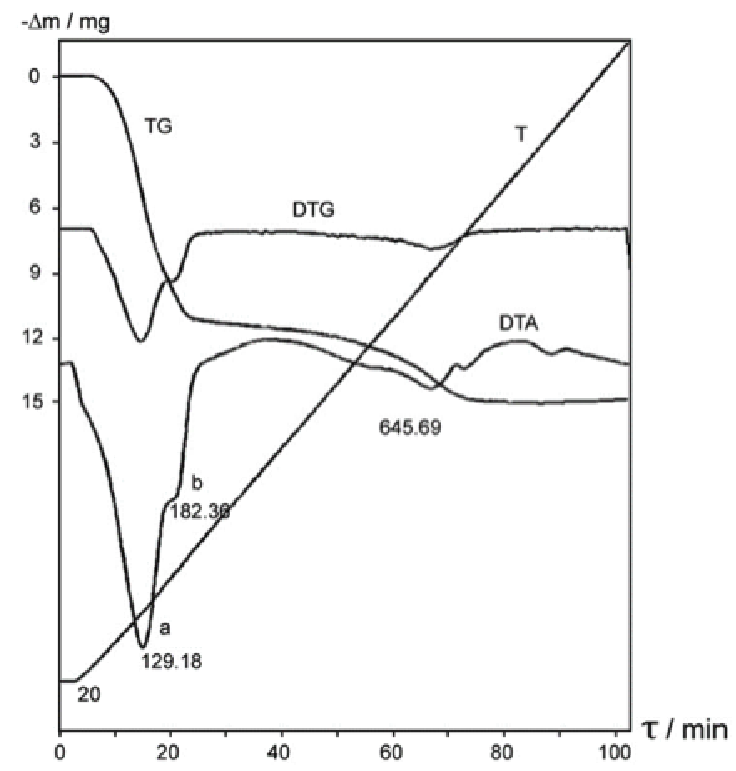

Fig. 1. Derivatograme of Ca-montmorillonite.

The purpose of this paper was to elaborate a rapid and simple method for estimate the hydrated/hydrolyzed state of the interlayer cations in the montmorillonite using data from derivatograme and proposed for this, mathematical formulas. The mass losses corresponding of thermal effects $a$ and $b$ on DTA curve (Fig. 1), are different for each of the exchangeable cation species in the montmorillonite and serve as characteristics of these homoionic modified samples.

\section{Results and Discussions}

Let's assume that, using thermal analysis, the contents of adsorption water of the first and second kind in a sample of montmorillonite are found to be $C_{a}$ and $C_{b}$ percents, respectively (Fig.1). Thus $100 \mathrm{~g}$ of the mineral contains the following number of Moles of both kinds of water:

$$
C_{a}+C_{b}=\frac{a}{\mu_{\mathrm{H}_{2} \mathrm{O}}}+\frac{b}{\mu_{\mathrm{H}_{2} \mathrm{O}}}
$$

In the sample with arbitrary mass $m$ are (Moles):

$$
C_{a}+C_{b}=\frac{a m}{100 \mu_{\mathrm{H}_{2} \mathrm{O}}}+\frac{b m}{100 \mu_{\mathrm{H}_{2} \mathrm{O}}}
$$

Since a Mole of any substance contains $A=6.02 \cdot 10^{23}$ molecules (Law of Avogadro), we obtain that the number of water molecules in a mineral sample of mass $m$ is:

$$
N_{a}+N_{b}=\frac{a m A}{100 \mu_{\mathrm{H}_{2} \mathrm{O}}}+\frac{b m A}{100 \mu_{\mathrm{H}_{2} \mathrm{O}}}
$$

Adsorbing quality of montmorillonite is characterized by cation-exchange capacity $E$, i.e. the amount of adsorbed ion expressed in milliequivalents ( $m e q$ ) which is contained in $1 g$ of adsorbent. If $1 g$ of adsorbent contains $E$ (meq) amount of cation, then the sample of $m$ grams contains $E m$ (meq) of cation. Multiplying by chemical equivalent $\varepsilon$ and dividing by 1000 , we obtain the mass of the cation in the sample expressed in grams:

$$
m_{c}=\frac{E m \varepsilon}{1000}
$$

Multiplying (5) by $A$ (number of Avogadro) and dividing by molecular mass $\mu_{c}$ of the cation, we obtain the number of exchangeable (interlayer) cations in the sample of the adsorbent:

$$
n_{c}=\frac{E m \varepsilon A}{1000 \mu_{c}}
$$

Dividing (4) by (6) produces the formula for calculating the number of water molecules per exchangeable cation in the sample of montmorillonite:

$$
N_{\mathrm{H}_{2} \mathrm{O} / \mathrm{cat}}=\frac{\left(N_{a}+N_{b}\right)}{n_{c}}=\frac{(a+b) m A}{100 \mu_{\mathrm{H}_{2} \mathrm{O}}} \cdot \frac{1000 \mu_{c}}{E m \varepsilon A}=\frac{10(a+b) \mu_{c}}{E \varepsilon \mu_{\mathrm{H}_{2} \mathrm{O}}}
$$

Observation: In the formula (6) the chemical equivalent can be replaced with its value:

$$
\varepsilon=\frac{\mu_{c}}{z}
$$

We obtain the following:

$$
n_{c}=\frac{E m A}{1000 \mu_{c}} \cdot \frac{\mu_{c}}{z}=\frac{E A m}{1000 z}
$$

The formulas (6) and (9) shows that the number of cations in the interlayer space of montmorillonite depends on the nature and the electric charge of the cation, and that the finding of the exchangeable cations in the mineral is an 
electrically compensatory phenomenon. Taking into account the formulas (3) and (5), we can receive from (6) a new (modified) formula:

$$
N_{\mathrm{H}_{2} \mathrm{O} / \mathrm{cat}}=\frac{10(a+b) z}{E \mu_{\mathrm{H}_{2} \mathrm{O}}}
$$

The number of the water molecules surrounding a cation of the chemical species is called the hydration degree of this cation. Comparing formulas (1) and (10) we see that:

$$
A_{m}=\frac{10(a+b)}{\mu H_{2} O}=\frac{10}{16}(a+b)=0.56(a+b)
$$

This formula (11) allows formal to calculate the maximum monolayer adsorption of water vapors according to BET

$$
N_{\mathrm{H}_{2} \mathrm{O} / \mathrm{Al}}^{3+}=\frac{10(8+7) 3}{1 \cdot 18}=25, \text { and, } N_{\mathrm{H}_{2} \mathrm{O} / \mathrm{Al}(\mathrm{OH})^{2+}}=\frac{10(8+7) 2}{1 \cdot 18}=16.7
$$

As can be seen from these results, the calculated hydration degree of cations are close to each other [20], however they do not

\begin{tabular}{|c|c|c|c|c|c|c|c|c|c|}
\hline Cation & N coordin. & $\begin{array}{l}\mathbf{N} \\
\mathrm{H} 2 \mathrm{O} / \mathrm{M}^{\mathrm{n}+} \\
\end{array}$ & $\begin{array}{l}\mathrm{N}_{\mathrm{H} 2 \mathrm{O}} \\
{ }_{(\mathrm{M}-\mathrm{M}-\mathrm{OH})+}\end{array}$ & $\begin{array}{l}\mathbf{R}_{M^{n+}} \\
\mathbf{n m}\end{array}$ & $\begin{array}{l}\Delta \mathrm{d}_{001}, \\
\mathrm{~nm}\end{array}$ & $\begin{array}{l}\text { pH } \\
\text { susp. (1\%) }\end{array}$ & $\begin{array}{l}\text { Ratio } \mathrm{H}_{2} \mathrm{O} \\
\mathrm{C}_{\mathrm{a}} / \mathrm{C}_{\mathrm{b}}\end{array}$ & $\begin{array}{l}A_{\mathrm{m}}, \\
\mathrm{mMoles} / \mathrm{g}\end{array}$ & $\mathbf{H}$ \\
\hline \multirow{2}{*}{$\mathrm{Na}^{+}$} & \multirow{2}{*}{$3,4,6$} & 3.9 & - & \multirow{2}{*}{0.101} & 0.35 & - & - & 3.9 & - \\
\hline & & 6.1 & - & & 0.30 & 9.8 & $11 / 0$ & 6.16 & - \\
\hline \multirow{2}{*}{$\mathrm{Ca}^{2+}$} & \multirow[t]{2}{*}{6,8} & 15.4 & - & \multirow{2}{*}{0.105} & 0.62 & - & - & 7.7 & - \\
\hline & & 13.3 & 1.8 & & 0.50 & 8.2 & $12 / 3$ & 8.40 & 0.20 \\
\hline \multirow{2}{*}{$\mathrm{Al}^{3+}$} & \multirow{2}{*}{6} & 17.1 & - & & 0.62 & - & - & 5.7 & - \\
\hline & & 13.3 & 8,2 & 0.055 & 0.54 & 3.7 & $8 / 7$ & 8.40 & 0.47 \\
\hline $\mathrm{Fe}^{3+}$ & 6 & 8.3 & 10.6 & 0.067 & 0.49 & 2.8 & $5 / 9$ & 7.84 & 0.64 \\
\hline
\end{tabular}
correlate with the X-ray analysis data (Table 1).

Table 1. The processed data from literature and the results of the thermal analysis

Note relating to Table 1:

1. The values in odd lines are taken principally from [20]. The data were obtained on Montmorillonite Pyzhevskiy (Ukraine) using vacuum installation.

2. The values of $\mathrm{H}$ from the table means that $20 ; 47$ and 64 percents of the interlayer $\left(\mathrm{Ca}^{2+}, \mathrm{Al}^{3+}\right.$ and $\left.\mathrm{Fe}^{3+}\right)$ cations contains one hydroxyl group in their hydration sphere.

So large number of water molecules (20-25) per cation is unrealistically higs simply because it cannot represent a simple two layer of water molecules in the hydration sphere of this cation.

We are forced to assume that a part of di- and trivalent exchangeable cations is hydrolyzed, hence the calculation of the amount of water is erroneous because it doesn't take into consideration the new state of the cations having reduced electric charge.Therefore, we have made calculations for each mass loss corresponding to endothermal effect ( $a$ and $b-$ Fig.1), separately, considering that the first effect belongs of water molecules of non-hydrolyzed cations and the second one - of the water of complex ion $(M-O H)^{(n-1)+}$. The results are in the Table 1 . Knowing total water content $(a+b)$ and the percentage of each water types in the montmorillonite sample, we calculate the share of hydrolyzed cations, or the degree of hydrolysis of the interlayer cations:

$$
H=\frac{b}{(a+b)}
$$

It is well known that liquid water contains molecular complexes linked by hydrogen bonds in the shape of dimers and other geometrical structures - linear as well as cyclic (clusters) [21-26]. The polar water molecules are oriented along the electric field lines of the ion and their electronic shells are strongly distorted (especially when hydrogen bonds are present) which leads to breaking of other bonds - the chemical ones. This can be illustrated by the following scheme of the process:

$$
\mathrm{M}^{\mathrm{n}+} \ldots \prod_{\mathrm{H}}^{\mathrm{O}}-\mathrm{H} \cdots 2 \prod_{\mathrm{H}}^{\mathrm{O}} \rightleftharpoons \mathrm{H} \rightleftharpoons(\mathrm{M}-\mathrm{OH})^{(\mathrm{n}-1)+}+\mathrm{H}_{3} \mathrm{O}^{-}
$$

where $M^{n+}$ is the interlayer exchangeable cation, $1-$ the shortening, 2 - the lengthening of bindings. The nearest from cation water molecule is one of those molecules that are in its first coordination sphere, while the second one is respectively one of the molecules from extern coordination sphere. So process is a cationic hydrolysis and it is typical for transition metal cations with an incomplete $3 d, 4 d$ or $5 d$ electronic layer, and for amphoteric cations having vacant $p$-orbitals. The presence of water molecules in the first coordination sphere of cations is evidenced in the IR spectrum of montmorillonite as a band of valence $O-H$ oscillations in the interval of $3440-3100 \mathrm{~cm}^{-1}$ depending on the nature of cations. The molecules from the extern sphere are in the spectrum an $O-H$ band in the interval $3370-3500 \mathrm{~cm}^{-1}$ [27].

The difference in energy states of the $O-H$ groups in the 
water molecules with or without hydrogen bonds was evidenced by the analysis of montmorillonite IR spectrum. The first of these are highlighted by a broad absorption band in the interval $3400-3440 \mathrm{~cm}^{-1}$ and the others (without $\mathrm{H}$-bonds) - by narrow band with maximum of IR absorption at 3630 $\mathrm{cm}^{-1}[28]$.

It is known that the water molecules from the second (extern) sphere of cations are under the influence of the surface electric field of the mineral layers. These molecules also can forms the hydrogen bonds with oxigen on these layers [29]. The $\mathrm{SiO}_{4}$ tetrahedra of the montmorillonite are associated into ditrigonal lattice with the chavities-hexagons. The configuration of electon orbitals of the oxygen atoms of these hexagons (on the tetrahedral sheet) gives the cavities a character of Lewis bases [30]. These properties are more pronounced in the case of isomorphic substitutions in the montmorillonite structure, especially in the octahedral layer. Due to this fact it is possible to complex dipolar water molecules and their transformation:

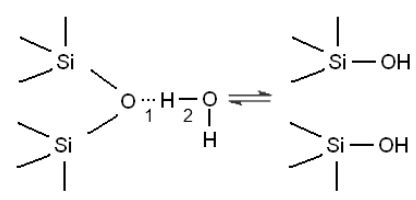

where 1 - is the shortening and 2 - the lengthening (up to breaking) of the bindings.

The suspensions of the better part of cationexchanged samples of montmorillonite have low $p H$ values, but not the suspensions of samples with alkali metal ions. The hydrolysis process in these types of mineral haves the anionic origin, and can be explained by the following. The $\mathrm{Na}^{+}$cation (for example) have a small potential $(z / r)$, a spheric symmetry of the extern electrons, no property to polarize and to accept electrons, so it does not hydrolyze as shown in the scheme (14). Its state is only hydrated. The interlayer complex of montmorillonite can be compared with the concentrated salt solution, which volume is equal of the basis of a structural unit of the mineral multiplied by the interlayer spacing $\Delta d_{001}$. More precisely, we have a solution in a bowl (a cell) whose walls serve as anion. Therefore, the effect of hydrolysis is the result of the competition of the exchangeable cations and the basal face of the tetrahedral sheet of the montmorillonite (and maybe of the edges of the particles) in the polarization of water molecules, and this process is accompanied by another one - the donation-acceptance of protons of the associated molecules. Taking into account the above mentioned the state (and the role) of the interlayer cations can be more correctly rendered as follows:

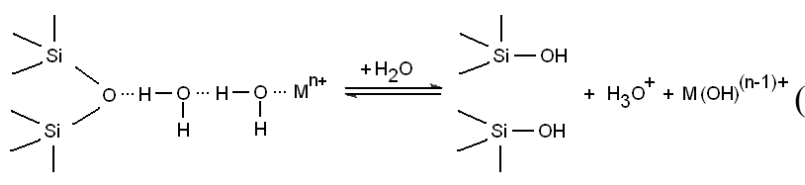

Note: Explications regarding the number of water molecules involved in the processes, here and below, see the scheme (14).
In particular, for alkali metal cations can be used another chemical scheme of process:

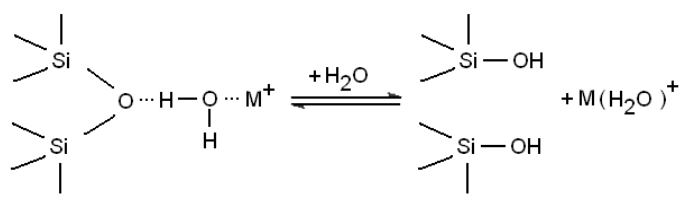

The hydration of the siloxane groups and appearance of free from mineral matrix a cations has the effect of the shifting the equilibrium of the electric charges in the system, here is why the suspension responds by changing the $p H$. It is necessary to note, that the siloxane groups on basal face of the mineral layer are considered inactive in the protonation processes, and in this case the emphasis is on the functional groups from the edges of montmorillonite particles. From the other hand, it is known that the reactivity of the siloxane surface depends on the nature of the local charge distribution [31] in the clay layer. In [32,33] authors point out that in case if isomorphic substitutions occur in the octahedral sheet, the resulting excess negative charge makes it possible for the surface to form reasonably strong adsorption complexes with cations and water molecules.

The hydrolysis of the cation depends upon its nature: charge, radius and electonegativity [34], and is considered as a process in equilibrium characterized by the constant $K_{a}$ or its logarithm:

$$
\begin{gathered}
p K a=15.14-0.8816\left(\mathrm{z}^{2} / \mathrm{r}\right) \\
p K a=15.14-0.8816\left[\left(\mathrm{z}^{2} / \mathrm{r}\right)+9.60(\chi-1.50)\right]
\end{gathered}
$$

where $z, r$ and $\chi$ are the charge, radius and Pauling electronegativity. In conditions that $p H=p K_{\alpha}$, about the half of the cations can be hydrolyzed. Comparing the $p H$ of the suspensions (Table 1) and $p K_{\alpha}$ values of the exchangeable cations we can observe that these values descreases according to the same natural law and this suggest the hydrolyzed state of the part of the cations (for example, respective $p K_{\alpha}$ of cations $\mathrm{Na}^{+}, \mathrm{Ca}^{2+}, \mathrm{Al}^{3+}$ and $\mathrm{Fe}^{3+}$ are: $14.2 ; 12.8 ; 5.0 ; 2.2$ [34]) However, it should be noted that due to the specific conditions in the interlayer space of the dry mineral, the value of hydrolysis constant of cations can be different than in aquaeous solutions.

The formed in hydrolysis process $\mathrm{H}_{3} \mathrm{O}^{+}$- ion can interact with basic groups from lateral faces of the montmorillonite particles according to the follouing scheme, thereby influensing the cationic exchange capacity:

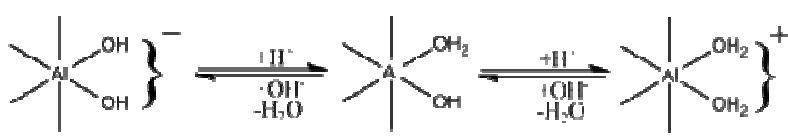

The possibility of such processes $(14-17,20)$ on the surface of montmorillonite is confirmed by the $\mathrm{pH}$ of the suspension (Table 1) as well as adsorption and ion exchange phenomena, dependent on the value of $p H[28,35]$. As shown in the Table 1 , the calculation of the hydration degree of the hydrolyzed interlayer cations using thermal analysis is closer to value 
obtained from the adsorption ishoterm using formula (1). This also confirms the hydrolyzed state of the fraction of these cations, although the authors [20] have not taken into account in this case the possibility of the hydrolysis.

\section{Conclusions}

1. The interlayer exchangeable cations in the montmorillonite are hydrated and a part of them can be hydrolyzed. This state is characteristic for polyvalent cations and the degree of hydrolysis depend of the species of the cation.

2. The use of thermal analysis data allows calculating the number of water molecules surrounding an exchangeable cation of the montmorillonite and indicates the state of them in the interlayer space.

3. Thermal analysis allows finding rapid the maximum value of monolayer adsorption of water vapors onto surface of the montmorillonite; that is important in the scientific study.

4. The proposed method for determining the degree of hydration and the hydrolyzed state of the interlayer cations is much easier, and having the special calculation program it is possible to automate the process.

\section{References}

[1] Handbook of clay science (eds. Bergaya F., Theng B.K.G. and Lagaly G.). Amsterdam: Elsevier Ltd., 2006.

[2] Clay Minerals in Nature: Their Characterization, Modification and Application. (eds.Valašcova M. and Martynkova G.S.). Rijeka: InTech., 2012, - 312 p. DOI: 10.5772/2708.

[3] Wilson M.J. Rock-forming minerals. V.3C (second ed.). Sheet Silicates: Clay Minerals. London: The Geolog. Society Publ. House, 2013, pp. 210-256.

[4] The practical importance of bentonite. www.activator.ru/rus/5.php.

[5] McKeown Nancy K., Bishop Janice L., Cuadros Javier, Hiller Stefen, Amador Elena, Macarewicz Heather D., Parente Mario, and Silver Eli A.Interpretation of reflectance spectra of clay mineral-silica mixtures: implications for Martian clay Mineralogy at Mawrth Vallis - Clays and Clay Minerals, 2011, v.59, pp. 400-415.

[6] McKeown Nancy K. Water on ancient Mars: Forming the phyllosilicates (dissertation). udini.proquest.com/view/Water-on-ancient-mars-forming-thegoid: 751246813 .

[7] Render D. Chemistry in Space: From Interstellar Matter to Origin of Life. Weinheim : Willey-VCH Verlag \& Co.Kga, 2010, - $291 \mathrm{p}$.

[8] Ostrowski D.R., Lacy C.H., Gietzen K.M. and Sears D.W.G IRTF spectra for 17 asteroids from $\mathrm{C}$ and $\mathrm{X}$ complexes: A discussion of continuum slopes and their relationships to chondrites and phillosilicates. - Icarus, 2011, v.212, No 2, pp. 682-696.

[9] Rietmeiyer F.J.M., Thiel K. An experimental study of phyllosilicate modification in comets during perihelion could be relevant to ferric iron-rich layer silicate formation at the martian surface. - Ground From Mars (2008). www.lpi.usra.edu/meetings/msr 2008/pdf/4008.pdf.

[10] Lisandro J., Campins H., Mothé-Diniz T.,Pinilla-Alonso N., and de Leon J.. The nature of comet-asteroid transition object (3200) Phaethon. - Astronomy and Astrophysics, 2007, v.461, No 2, pp. 751-757.

[11] Saladino R., Crestini Claudia, Ciambecchini U., Cicirello F., Constanzo G., and Di Mauro E. Synthesis and Degradation of Nucleobases and Nucleic Acids by Formamid in Presence of Montmorillonite.- ChemBioChem., 2004, No 5, pp. 1-9.

[12] Ferris J.P. Mineral Catalysis and Prebiotic Synthesis: Montmorillonite - Catalized Formation of RNA - Elements, 2005, v.1, pp. 145-149.

[13] Ferris J.P. Montmorillonite - catalysed formation of RNA oligomers: the possible role of catalysis in the origin of life. Phil. Trans. Soc. B., 2006, v.361, No 1474, pp.1777-1786.

[14] Hashizume H. Role of Clay Minerals in Chemical Evolution and the Origin of Life In.: Clay Minerals in Nature: Their Characterization, Modification and Application. (eds.Valašcova M. and Martynkova G.S.), chapter 10. Rijeka: InTech., 2012.

[15] DOI: $10.5772 / 50172$.

[16] Bishop J.L. and Murad E. Characterization of mineral and biogeochemical markers on Mars: A Raman and IR spectroscopic study of montmorillonite. - Journal of Raman Spectroscopy, 2004, v. 35, pp. 480 - 486. DOI: $10.1002 /$ jrs. 1173 .

[17] Hoang-Minh Thao. Characterization on Clays and Clay Minerals for Industrial Applications: Substitution non-Natural Additives by Clays in UV Protection (dissertation). Greifswald (Germany), 2006, - 168 p. (d-nb.info/984459022/34).

[18] Földvári M., Kovács-Pálffy P., Nagy N.M., Konya J. Use of the second derivative of $\mathrm{TG}$ curves for investigation of the exchanged interlayer cation in montmorillonite. - J. Thermal Anal., 1998, v. 53, pp. 547-558.

[19] Yan L., Xiajun W. and Juanfang W. Cation exchange, interlayer spacing, and thermal analysis of $\mathrm{Na} / \mathrm{Ca}$ - montmorillonite modified with alkaline and alkaline earth metal ions. J.Thermal Anal. Calorimetry, 2012, v.110, No 3, pp.1199-1201.

[20] Maftuleac A., Dranca I. and Lupaşcu T. Study of interlayer water on the active sites of mineral sorbent. - Journal Thermal Anal. Calorimetry, 2002, v.69, pp. 589-598.

[21] Tarasevich Iu.I. and Ovcharenko F.D. Adsorbtion onto clay minerals. Kiev: Naukova dumka, 1975, - 351 p. (in Russian).

[22] Kuyanov-Prozument K., Choi Vong Myong and Vilesov A.F. Spectrum and intensities of $\mathrm{OH}$-strenching bands of water dimmers. - J. Chem. Phys.,v.132, 014304(2010). DOI: 10.1063/1.3276459.

[23] Lo Sh.Y., Geng X. and Gann D. Evidence for the existence of stable-water-clusters at room temperature. - Phys. Letters A, 2009, DOI: 10.1016/j.physleta2009.08061.

[24] Zakharov S.D. and Mosyagina I.V. The cluster structure of water. Moscow: Preprint, Lebedev Phys. Inst. Acad. Sci., (prints.lebedev.ru/wp-content/uploads/2011/12/35_11_pr.pdf). 2011, - 26 p. (in Russian). 
[25] Sinyukov V.V. The structure of monoatomic liquids, water and aqueous solutions of electrolytes. Moscow: Nauka, 1976, - 256 p. (in Russian).

[26] Zundel G. Hydration and Intermolecular Interaction. Infrared Investigation with Polyelectrolyte Membranes. N.Y.- London: Academic Press, 1969 (in Russian: Mir, 1972).

[27] Melnichenko N.A. Modern ideas about the structure of water and aqueous solutions of electrolytes, including seawater. Vladivostok: Publ. Far East. Univ., 2009, - 76 p. (in Russian).

[28] Tarasevich Iu.I. The natural sorbents in water treatment processes. Kiev: Naukova dumka, 1981, - 207 p. (in Russian).

[29] Tarasevich Iu.I. Surface structure and chemistry of layer silicates. Kiev: Naukova dumka, 1988, - 247 p. (in Russian).

[30] Osipov V.I., Sokolov V.N. and Rumyantseva N.A . Microstructure of the clay rocks. Moskow: Nedra, 1989, pp. 61-64. (in Russian).

[31] Velde B. and Meuner A. The Origin of Clay Minerals in Soils and Weathered Rocks. Berlin, Heidelberg: Springer-Verlag, 2008. (Chapter 1.5.2, The Cristallite Outer Surface).
[32] Sposito G. The surface chemistry of soils. Oxford Univ. Press., New York, 1984.

[33] Sposito G., Skipper N.T., Sutton Rebecca et al. Surface geochemistry of the clay minerals.- Proc. Nat. Acad. Sci. USA, 1999, v.96, pp. 3358-3364.

[34] Avena M.J. Acid-Base Behavior of Clay Surface in Aqueous Media. In: Encyclopedia of Surface and Colloid Science, v.3, (ed.Somasundaran P.), UK: Taylor and Francis, 2006, pp. 17- 46 .

[35] Gerken M. Hydrolysis of cations and acidity of aqua complexes of metal cations. In: Chemistry 2810 Lecture Notes, (classes.uleth.ca/200501/chem2810a/lecture_8.pdf).

[36] Maftuleac A., Lupaşcu T., and Motoc V. Adsorption of Fulvic Acids on Montmorillonite and its Dependence on $\mathrm{pH}$. - Bull. Acad. Sci. of Moldova (Biol.,Chem.), 1996, No 2, pp. 54-59. (in Romanian). 